\section{I knew you wouldn't mind}

S Hancocks, OBE*

\author{
Bumping into patients away from the practice and having to talk \\ dentistry is one thing, having to answer the questions of friends \\ is quite another.
}

The curious thing is that patients very rarely ask you dental questions outside the confines of the surgery. It may be due to the fact that they are mildly embarrassed or that they don't recognise you with your clothes on, as it were. Possibly they just don't have anything they want to know or they are sufficiently sensitive to realise that you are not at work. Friends and acquaintances on the other hand have no such scruples.

It can happen anytime, anywhere. In the supermarket, on the touchline at your child's sports team debut, at the airport, anywhere in fact when dentistry is the last thing that you want to talk about. It usually runs something like this: 'Well if it isn't [insert your name here], how lovely to see you again, your inquisitor-to-be bounds forward in the shop, on the field or at the departure gate. You greet them with an equal amount of pleasure, unaware at that moment of the impending direction in which the conversation is about to treck off. 'No,' you venture in the spirit of human generosity for which you are universally known, 'it's been ages. How have you been?' This is the fatal slip, the Achilles heel of what you and I know as conversation but what learned psychologists term personal interactive exchange encounters, probably so that no one stops and asks irritating questions about Freudian theories of them on a Saturday morning near the chilled meat cabinets.

The old friend has been well, very well in fact...except for this terrible tooth problem. 'I know you're off duty,' they bluster, 'and I wouldn't normally (so don't! - this starts to sound familiar as you cotton-on to what is coming next) and so I shouldn't trouble you with it now.' And then they do.

It has started in a heavily filled lower molar, or an ancient anterior crown, or in an unfathomable location which they try and describe as they point in and backwards while you bob and weave enough to just miss your child's first shot at goal and see it glance off the post. A long saga of an inability to get an emergency appointment then follows. This is likely to include detailed reconstructions of missed meetings, cancelling anniversary celebrations or attending an out of the way practice on a wind swept November night when the power lines were down due to a particularly fierce Atlantic storm (with sound effects).

You grimace undiscernibly as you see the last uncut wholemeal loaf disappear off the shelf only feet ahead of you, but which might as well be half way around the world for
the time it is going to
take you to get that far.

You grimace undiscernibly as you see the last uncut wholemeal loaf disappear off the shelf only feet ahead of you, but which might as well be half way around the world for the time it is going to take you to get that far.

Whatever the operation, for operation it will have been, no simple one-off visit for a problem of this magnitude, it will have "not gone quite according to plan.' You feel a twitch in the diplomatic lobe of your professional ethics grey matter. It seems that 'the new dentist' is not to be blamed for the agony that your friend has been put through, he was

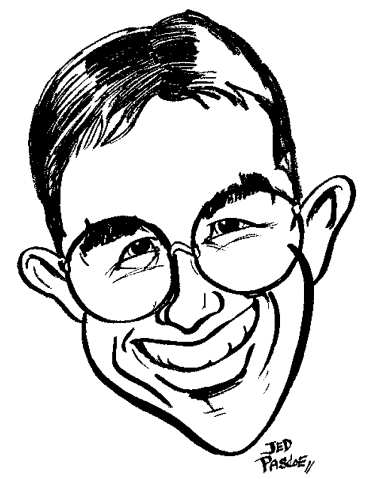

clearly doing his best under very difficult circumstances in a situation that was probably 'something of a mystery to dental science' (apparently). You have your doubts as you hope against hope that it is soon time for your flight to be called and that the charming check-in operative hasn't seated the two of you together for the duration of the eighthour flight.

'Well, then he got out these needle looking things and started poking about with them (endo files you surmise) which was fine until I got this terrible pain shooting up here.' This chapter is accompanied by a finger aimed up the nose towards the brain and distracts you completely as goal number one is scored. You start calculating how, over dinner that night, you can possibly tell your youngest born that the reason you missed their moment of sublime triumph was because some buffoon in mauve tracksuit bottoms was showing you their infra-orbital fossa.

'Then I nearly jumped out of the chair. The pain! (not enough anaesthetic?) Apparently there wasn't enough anaesthetic.' It is only thinking of the GDC that enables you to suppress a smirk. 'So another injection and ... and...' and another batch of crustytopped farmhouses have found new owners, one of whom is not you.

This news comes as a considerable relief. Of course they didn't really think there was anything untoward at all but it is so reassuring to be able to talk it over with a friend who has the inside, professional knowledge.

'Last call for flight BQ 23'. Heaven sent. You have to go now but as they shake your hand fervently and wish you a great holiday they still have the last word, 'I'm so sorry to have bothered you ... but I knew you wouldn't mind.'

* The author is commissioning editor for the $\mathrm{BDJ}$. 